\title{
RESPONSES OF SOIL RHIZOSPHERE FUNGI TO N APPLICATION LEVELS IN DIFFERENT TYPES OF SOIL
}

\author{
LI, Y. N. ${ }^{1,2}-$ WANG, T. Y. ${ }^{1}-$ WANG, C. Y. ${ }^{1,2}-$ LI, M. S. ${ }^{1,2}-$ WANG, Y. ${ }^{*}-$ LIU, S. X. ${ }^{12^{*}}$ \\ ${ }^{1}$ College of Resources and Environment, Jilin Agricultural University, Changchun 130118, China \\ ${ }^{2}$ Key Laboratory of Soil Resource Sustainable Utilization for Jilin Province Commodity Grain \\ Bases, Changchun 130118, Jilin Province, China \\ *Corresponding authors \\ e-mail/phone: wangyujlc@163.com/+86-135-0446-8360; liushuxia69@163.com/+86-155-4313- \\ 3987
}

(Received $16^{\text {th }}$ Sep 2020; accepted $19^{\text {th }}$ Jan 2021)

\begin{abstract}
The response of maize soil rhizosphere fungi to different $\mathrm{N}$ application levels (0, 168, 240, 270 , and $312 \mathrm{~kg} \cdot \mathrm{ha}^{-1}$ ) in sandy, meadow and alluvial soils were investigated by sequence variations in ITS rDNA determined with Illumina MiSeq sequencing. The result showed that with $\mathrm{N}$ application levels increased, soil available nutrients changed significantly, but total nutrients changed little, and the nutrient content site in meadow soil was higher than that in sandy soil and alluvial soil. The rhizosphere fungal community was mainly composed of Ascomycota and Basidiomycota. $\mathrm{N}$ application did not change the relative abundance of fungi significantly, but altered the structure of fungal communities. The relative abundance of Basidiomycota was increased with $\mathrm{N}$ application. Moreover, $\mathrm{N}$ application also increased fungal pathogens: Alternaria, Rhizopus and Waitea significantly. In addition, the soil fungal communities were clustered into two main groups, one for the meadow soil sites and another for the sandy soil and alluvial soil sites. Soil fungal community structure changed when nitrogen application level exceeded $168 \mathrm{~kg} \cdot \mathrm{ha}^{-1}$. Our findings on the responses of fungal community to $\mathrm{N}$ application levels in different types of soil is important to determine rational fertilization application measures.
\end{abstract}

Keywords: soil fungi, $N$ fertilizer application, different types of soil, fungal diversity, fungal structure

\section{Introduction}

Nitrogen $(\mathrm{N})$ is an important nutrient element in plants, and it has a major impact on plant productivity and fungal function (Wilson, 2013). According to the National Bureau of Statistics, China's fertilizer production was 76,276,600 tons in 2015, which was an increase of more than $7.3 \%$ from 2014; The current annual nitrogen fertilizer production is 49,438,500 tons, which represents an increase of more than $6.3 \%$ from the previous year and is the largest increase in recent years $(\mathrm{Li}, 2018)$. The contribution rate of chemical fertilizer application to grain production is over $40 \%$ in China due to the low base soil fertility (Tian et al., 2018). Long-term fertilization can not only increase soil nutrients but also improve crop quality and promote microbial activity. In recent years, due to the neglect of the application of organic fertilizers, increasing crop yields has increasingly relied on excessive application of nitrogen fertilizers; however, excessive nitrogen application has various negative effects on soil quality, crop yield and the ecological environment (Qu et al., 2019; Zheng et al., 2013). Studies have shown that the excessive application of nitrogen fertilizer not only increases production costs but also reduces soil nutrient sustainability and nitrogen use efficiency and has a significant impact on environmental factors such as greenhouse gas emissions (Lijbert et al., 2007). Fertilizer application has a significant impact on soil fungal activities, especially soil fungal denitrification (Yamamoto et al., 2017). Different fertilization 
systems have significant effects on soil fungal population and community structure (Zhao et al., 2014)

Fungi are important components of soil communities and play an important role in agro-ecosystems (Wood et al., 2015; Joergensen et al., 2008). During decomposition, fungi can break down plant residues and difficult-to-decompose compounds such as cellulose, hemicellulose, and lignin, which are complex and closely related to vegetation, and can release nutrients needed for plant growth because of their high extracellular enzyme activity and comprehensive range of enzymes. Fungi not only affect the cycling of the nutrients $\mathrm{C}, \mathrm{N}$ and $\mathrm{S}$ but also provide plant nutrition, promote plant growth and inhibit disease. It has been reported that between $78 \% \sim 90 \%$ of the biomass in grass is decomposed by fungi (Kowalchuk et al., 1997). This indicates that fungi promote the circulation of nutrients. Fungi are more sensitive than soil bacteria to changes in the environment (Sall et al., 2006). Fungi have advantages in adapting to climate and environmental changes (Qu et al., 2019; Laura et al., 2012) due to the special structural characteristics of soil fungal hyphae.

Soil rhizosphere microorganisms are a key link between the soil and plant nutrient supplies. Microorganisms are concentrated around the roots, transforming the organic matter released during plant growth into inorganic matter and providing effective nutrition for plants (Xu et al., 2008). Studies have shown that the major groups of soil rhizosphere fungi are Penicillium, Trichoderma, Aspergillus, Pythium, Gliocladium and Fusarium, but their specific species vary widely (Zhang et al., 2010). Nitrogen application also significantly changes the community structure of soil fungi (Zhang et al., 2018). Chanyarat et al. (2015) have shown that nitrogen application strongly changed the population structure of soil fungi, with the increase of nitrogen fertilizer having potential negative effects on the soil carbon and nitrogen cycle; excessive application of nitrogen fertilizer also increased the proportion of pathogenic fungal species. The results of Zhou et al. (2016) and Bi et al. (2010) also showed that the longterm application of nitrogen fertilizer not only reduced the diversity of soil fungi but also changed the fungal community composition. However, the change in the soil rhizosphere fungal community in different types of soil with the same fertilization application levels has not been investigated sufficiently.

Reasonable nitrogen fertilizer application is a concern of an increasing number of agricultural producers. Lishu, Jilin Province, China is the national key commodity grain production base, and sustainable cultivation of corn is crucial in this region, the contribution of Jilin province to Chinese total production is about 15\% (Lin et al., 2018). In this work, we conducted a field trial of maize cultivation for 9 consecutive years. We investigated the changes in the composition and diversity of the maize rhizosphere fungal community under the same climatic conditions in three soil types under different long-term nitrogen application levels based on sequence variation of ITS rDNA using Illumina MiSeq sequencing. The results will provide a theoretical basis for rational $\mathrm{N}$ application in different types of soil.

\section{Materials and methods}

\section{Collection of soil samples and field experiments}

Soil samples were collected from Lishu County, Siping city, Jilin Province, Northeast China $\left(123^{\circ} 45^{\prime}-124^{\circ} 53^{\prime} \mathrm{E}, 43^{\circ} 02^{\prime}-43^{\circ} 46^{\prime} \mathrm{N}\right)$. The area has a temperate 
continental monsoon climate, with four distinct seasons. The average annual rainfall is $594.8 \mathrm{~mm}$ and the average temperature is $5.6^{\circ} \mathrm{C}$. The main farming method this region is continuous cultivation of corn. There are three types of soil in the area: sandy soil (S) in Fujia Street village, meadow black soil (M) in Sankeshu village and alluvial soil (A) in Wangjiaqiao village.

There were five fertilization treatments in each soil: (1) N0 (no fertilization), (2) $\mathrm{N} 168\left(\mathrm{~N}, 168 \mathrm{~kg} \cdot \mathrm{ha}^{-1}\right)$, (3) N240 (N, $\left.240 \mathrm{~kg} \cdot \mathrm{ha}^{-1}\right)$, (4) N270 (N, $\left.270 \mathrm{~kg} \cdot \mathrm{ha}^{-1}\right)$, and (5) $\mathrm{N} 313\left(\mathrm{~N}, 313 \mathrm{~kg} \cdot \mathrm{ha}^{-1}\right)$. $\mathrm{N}$ fertilizer (urea) was applied to soil twice as basal fertilizer and as top dressing. Phosphate $\left(\mathrm{P}_{2} \mathrm{O}_{5}\right)$ and potassium $\left(\mathrm{K}_{2} \mathrm{O}\right)$ fertilizers were applied as basal fertilizer at rates of $100 \mathrm{~kg} \cdot \mathrm{ha}^{-1}$ and $120 \mathrm{~kg} \cdot \mathrm{ha}^{-1}$, respectively. Each treatment was repeated three times, with random permutation. All plots were planted with the Xianyu 335 corn variety. It was sown in April of each year, and all corn residues were removed from the plot after harvesting in October.

The soil samples were collected after the harvest period. To investigate the response of fungal communities for different soils, each plot was sampled at 5 points, and the samples were mixed into one sample, for a total of 15 test samples; Another15 test samples were obtained to investigate the effect of $\mathrm{N}$ application level on soil fungi (each treatment was took 3 samples). The maize rhizosphere soil were collected in polyethylene bags and then shaken vigorously by hand for 10 min until the non-adhering soil fell off. All samples were conserved on ice and taken back to the laboratory. Aliquots of 5 to $10 \mathrm{~g}$ of soils were directly shock frozen in liquid nitrogen after sampling and stored at $-80{ }^{\circ} \mathrm{C}$ until DNA extraction. The remaining soil samples were conserved at $4{ }^{\circ} \mathrm{C}$ for analysis of the soil physicochemical properties after 2 weeks. Before analysis, the soil samples were air dried and sieved using a $2 \mathrm{~mm}$ mesh. Soil $\mathrm{pH}$, moisture content (MC), organic carbon content (SOC), total nitrogen (TN), available phosphorus (A-P), available potassium (A-K) were measured by Soil agrochemical analysis. Ammonium nitrogen $\left(\mathrm{NH}_{4}{ }^{+}-\mathrm{N}\right)$ and nitrate nitrogen $\left(\mathrm{NO}_{3}^{-}-\mathrm{N}\right)$ were measured by a continuous flow analyser (Skalar San++, Netherlands) (Cui et al., 2018).

\section{Extraction and detection of soil nucleic acids}

Total genomic DNA was isolated from $0.50 \mathrm{~g}$ of soil samples using the PowerSoil ${ }^{\circledR}$ DNA Isolation kit (MoBioLaboratories, Inc., Solana, CA, USA) according to the manufacturer's instructions, with some modifications (the centrifugation time was extended to $15 \mathrm{~min}$ in step 5). Extraction and purification of soil nucleic acids was performed by the TIAN quick Midi purification kit (TIANGEN). Next-generation sequencing library preparations and Illumina MiSeq sequencing were conducted at GENEWIZ, Inc. (Suzhou, China). DNA samples were quantified using a Qubit 2.0 fluorometer (Invitrogen, Carlsbad, CA, USA). An amount of 50-100 ng DNA was used to generate amplicons using a panel of primers designed by GENEWIZ (GENEWIZ, Inc., South Plainfield, NJ, USA). Multiple oligonucleotide primers were designed to anneal to the relatively conserved sequences spanning fungal ITS regions (the forward primer containing the sequence "ACCTGCGGARGGAT"; the reverse primer containing the sequence "GAGATCCRTTGYTRAA"). In addition to the ITS targetspecific sequences, the primers also contained adaptor sequences allowing the uniform amplification of the library, which had high complexity and was ready for downstream NGS sequencing on the Illumina Miseq platform. DNA libraries were validated by an Agilent 2100 Bioanalyser (Agilent Technologies, Palo Alto, CA, USA) and quantified by Qubit 2.0 fluorometer. DNA libraries were multiplexed and loaded on an Illumina 
MiSeq instrument according to the manufacturer's instructions (Illumina, San Diego, CA, USA). Sequencing was performed using a $2 \times 300 / 250$ paired-end (PE) configuration; image analysis and base calling were conducted by the MiSeq Control Software (MCS) embedded in the MiSeq instrument. To ensure the purity of the measured DNA, we used agarose electrophoresis and determination of the extracted soil DNA and determined the absorbance of the soil DNA dilution at 230, 260 and $280 \mathrm{~nm}$ using an ultraviolet photometer (UV5 Nano, Switzerland).

\section{Statistical methods}

First of all, the original data were performed and filtered with low quality (sequence length $<200 \mathrm{bp}$, no ambiguous bases, mean quality score $\geq 20$ ). Then, clustering analysis was carried out, each cluster was called an operational taxonomic units (OTU). Alpha diversity indices were calculated in QIIME from rarefied samples using the Chao1 richness index, the Shannon diversity index, Simpson diversity and Goods coverage (Huang et al., 2019). An unweighted pair group method with arithmetic mean (UPGMA) tree was constructed from the beta diversity distance matrix (Deng et al., 2007). We also performed a redundancy analysis (RDA) using the to analyse the relationships between the environment, the samples and the top 30 most abundant fungal species (Zhang et al., 2018). To determine the effects of nitrogen fertilization on soil properties and fungal characteristics, statistical software (SPSS 21) was used to perform a one-way ANOVA and LSD tests.

\section{Results}

\section{The physical and chemical properties of the maize rhizosphere}

The physical and chemical properties of the three types of soil under different $\mathrm{N}$ application levels are shown in Table 1. The physical and chemical properties: Soil organic carbon (SOC), total nitrogen (TN), total nitrogen (TP), total potassium (TK), ammonium nitrogen $\left(\mathrm{NH}_{4}{ }^{+}-\mathrm{N}\right)$, nitrate nitrogen $\left(\mathrm{NO}_{3}{ }^{-} \mathrm{N}\right)$, available phosphorus (AP) and available potassium (AK) in meadow black soil were higher than that in the other two soil types, and $\mathrm{pH}$ was highest in alluvial soil; The physical and chemical properties were changed significantly with $\mathrm{N}$ application levels: when $\mathrm{N}$ application level arrived at $312 \mathrm{~kg} \cdot \mathrm{ha}^{-1}$, the $\mathrm{pH}$ decreased $6.3 \%$, the contents of $\mathrm{NH}_{4}{ }^{+}-\mathrm{N}$ and $\mathrm{NO}_{3}{ }^{-}-\mathrm{N}$ increased 1.7 and $5.62 \mathrm{mg} \cdot \mathrm{kg}^{-1}$. But the total nutrients (SOC, TN and TP) had no significant changes with the increasing $\mathrm{N}$ application levels ( $\mathrm{P}>0.05)$ (Table Al).

Table 1. Soil chemical properties of different types of soil

\begin{tabular}{c|c|c|c|c|c|c|c|c|c|c}
\hline & $\mathbf{p H}$ & $\mathbf{M C}$ & $\mathbf{S O C}$ & $\mathbf{T N}$ & $\mathbf{T P}$ & $\mathbf{T K}$ & $\mathbf{N H}_{4}{ }^{+}-\mathbf{N}$ & $\mathbf{N O}^{-}-\mathbf{N}$ & $\mathbf{A P}$ & AK \\
\hline S & $6.06 \pm 0.28 \mathrm{a}$ & $7.56 \pm 0.61 \mathrm{c}$ & $12.56 \pm 0.29 \mathrm{c}$ & $0.95 \pm 0.07 \mathrm{c}$ & $6.05 \pm 0.65 \mathrm{c}$ & $4.81 \pm 0.06 \mathrm{~b}$ & $2.57 \pm 0.84 \mathrm{~b}$ & $1.17 \pm 0.55 \mathrm{~b}$ & $90.45 \pm 31.54 \mathrm{~b}$ & $126.27 \pm 33.76 \mathrm{~b}$ \\
M & $5.93 \pm 0.31 \mathrm{ab}$ & $18.96 \pm 1.07 \mathrm{a}$ & $25.91 \pm 0.62 \mathrm{a}$ & $1.45 \pm 0.07 \mathrm{a}$ & $9.28 \pm 0.47 \mathrm{a}$ & $5.35 \pm 0.16 \mathrm{a}$ & $4.12 \pm 0.58 \mathrm{a}$ & $5.48 \pm 0.64 \mathrm{a}$ & $160.60 \pm 34.46 \mathrm{a}$ & $196.67 \pm 47.63 \mathrm{a}$ \\
A & $5.58 \pm 0.18 \mathrm{~b}$ & $13.24 \pm 0.65 \mathrm{~b}$ & $11.08 \pm 0.78 \mathrm{~b}$ & $1.10 \pm 0.10 \mathrm{~b}$ & $7.95 \pm 0.76 \mathrm{~b}$ & $5.11 \pm 0.22 \mathrm{a}$ & $2.82 \pm 0.11 \mathrm{~b}$ & $2.04 \pm 0.08 \mathrm{ab}$ & $141.22 \pm 32.86 \mathrm{a}$ & $120.93 \pm 30.26 \mathrm{~b}$ \\
$\mathrm{~N} 0$ & $5.83 \pm 0.13 \mathrm{a}$ & $13.72 \pm 1.57 \mathrm{a}$ & $12.71 \pm 0.84 \mathrm{a}$ & $1.11 \pm 0.38 \mathrm{a}$ & $5.20 \pm 0.49 \mathrm{a}$ & $2.78 \pm 0.35 \mathrm{~b}$ & $2.78 \pm 0.35 \mathrm{~b}$ & $0.67 \pm 0.42 \mathrm{~b}$ & $149.00 \pm 8.43 \mathrm{a}$ & $112.65 \pm 23.28 \mathrm{~b}$ \\
$\mathrm{~N} 168$ & $5.72 \pm 0.07 \mathrm{ab}$ & $13.80 \pm 1.00 \mathrm{a}$ & $12.90 \pm 0.61 \mathrm{a}$ & $1.20 \pm 0.09 \mathrm{a}$ & $5.45 \pm 0.43 \mathrm{a}$ & $2.27 \pm 0.13 \mathrm{~b}$ & $2.27 \pm 0.13 \mathrm{~b}$ & $0.94 \pm 0.68 \mathrm{~b}$ & $119.00 \pm 11.61 \mathrm{~b}$ & $194.88 \pm 15.87 \mathrm{a}$ \\
$\mathrm{N} 240$ & $5.48 \pm 0.09 \mathrm{ab}$ & $12.46 \pm 2.42 \mathrm{a}$ & $12.41 \pm 0.29 \mathrm{a}$ & $1.16 \pm 0.15 \mathrm{a}$ & $4.92 \pm 0.32 \mathrm{a}$ & $2.48 \pm 0.20 \mathrm{~b}$ & $2.48 \pm 0.20 \mathrm{~b}$ & $1.03 \pm 0.32 \mathrm{~b}$ & $113.67 \pm 7.51 \mathrm{~b}$ & $124.56 \pm 19.06 \mathrm{~b}$ \\
$\mathrm{~N} 270$ & $5.59 \pm 0.35 \mathrm{ab}$ & $12.62 \pm 1.41 \mathrm{a}$ & $12.14 \pm 1.75 \mathrm{a}$ & $1.07 \pm 0.09 \mathrm{a}$ & $4.98 \pm 0.19 \mathrm{a}$ & $2.00 \pm 0.94 \mathrm{~b}$ & $2.00 \pm 0.94 \mathrm{~b}$ & $1.19 \pm 0.44 \mathrm{~b}$ & $106.67 \pm 3.21 \mathrm{~b}$ & $124.56 \pm 27.42 \mathrm{~b}$ \\
$\mathrm{~N} 312$ & $5.46 \pm 0.04 \mathrm{~b}$ & $13.60 \pm 3.01 \mathrm{a}$ & $12.62 \pm 1.59 \mathrm{a}$ & $0.95 \pm 0.28 \mathrm{a}$ & $4.98 \pm 0.19 \mathrm{a}$ & $4.58 \pm 1.72 \mathrm{a}$ & $4.58 \pm 1.72 \mathrm{a}$ & $6.35 \pm 4.67 \mathrm{a}$ & $116.33 \pm 19.55 \mathrm{~b}$ & $149.47 \pm 36.96 \mathrm{ab}$ \\
\hline
\end{tabular}

The lower-case letters ' $a$ ' and ' $b$ ' indicate significant difference $(\mathrm{P}<0.05)$ among different samples for each treatment. " $\mathrm{S}$ " indicates sandy soil, "M" indicates meadow black soil and "A" indicates alluvial soil. MC is the moisture content of soil; SOC is Soil organic carbon content; TN is soil total nitrogen; TP is soil total nitrogen; TK is soil total potassium; $\mathrm{NH}_{4}{ }^{+}-\mathrm{N}$ is ammonium nitrogen; $\mathrm{NO}_{3}{ }^{-} \mathrm{N}$ is nitrate nitrogen; AP is available phosphorus; $\mathrm{AK}$ is available potassium 


\section{The fungal community diversity}

A total of 1.5 million sequences were obtained from the ITS gene sequencing, with a total gene base number of approximately $10^{8} \mathrm{bp}$. When grouped at the $97 \%$ similarity level, there were 630 OTUs for all of the soils. The number of OTUs in meadow black soil was higher than that in the other two soils. As the $\mathrm{N}$ application levels increased, the number of OTUs first increased then decreased, the highest under N168 (Table 2), and we found $\mathrm{pH}, \mathrm{SOC}, \mathrm{NH}_{4}{ }^{+}-\mathrm{N}, \mathrm{NO}_{3}{ }^{-} \mathrm{N}, \mathrm{TP}, \mathrm{TK}$ and $\mathrm{AK}$ had negative effect on the number of OTU (Table A2). The findings suggested that fungi were abundant in high quality soil. The fungal community alpha diversity in the three types of soil was different: the average Chao 1, Shannon and Simpson indices were highest in meadow black soil, and that was lowest in sandy soil $(p<0.05)$. The fungal community alpha diversity varied with different nitrogen applications: as the $\mathrm{N}$ application levels increased, the average Chao 1 index increased, but remained were lower than that under N0. The Shannon and Simpson index had no obvious change pattern under nitrogen application $(p>0.05)$ (Table 2). In order to discover which factors affected fungal community diversity, we analysed the correlations between alpha diversity indices and soil physical-chemical properties and $\mathrm{N}$ application levels. The correlation between fungal alpha diversity and soil physical-chemical properties was significant, especially SOC had significant effect on Chao 1 and Shannon index, but the correlation between fungal alpha diversity and $\mathrm{N}$ application level was not significant (Table A2). These findings indicated that the alpha diversity of fungal communities in this study was mainly influenced by the type of soil.

Table 2. The alpha diversity and OTU richness for $N$ application levels in three types of soil

\begin{tabular}{c|c|c|c|c}
\hline & OUT $\left(\times \mathbf{1 0}^{\wedge} \mathbf{4}\right)$ & chao1 & Shannon & Simpson \\
\hline A & $10.64 \pm 0.76 \mathrm{a}$ & $436.617 \pm 19.631 \mathrm{~b}$ & $5.319 \pm 0.259 \mathrm{ab}$ & $0.933 \pm 0.015 \mathrm{ab}$ \\
$\mathrm{M}$ & $9.18 \pm 0.46 \mathrm{a}$ & $489.906 \pm 26.071 \mathrm{a}$ & $5.814 \pm 0.453 \mathrm{a}$ & $0.957 \pm 0.018 \mathrm{a}$ \\
$\mathrm{S}$ & $9.77 \pm 0.15 \mathrm{a}$ & $452.877 \pm 22.968 \mathrm{~b}$ & $5.111 \pm 0.499 \mathrm{~b}$ & $0.914 \pm 0.032 \mathrm{~b}$ \\
N0 & $10.39 \pm 0.19 \mathrm{~b}$ & $476.653 \pm 18.633 \mathrm{a}$ & $5.421 \pm 0.384 \mathrm{a}$ & $0.938 \pm 0.017 \mathrm{a}$ \\
N168 & $11.87 \pm 0.03 \mathrm{a}$ & $429.807 \pm 26.164 \mathrm{~b}$ & $5.234 \pm 0.728 \mathrm{a}$ & $0.922 \pm 0.037 \mathrm{a}$ \\
N240 & $9.48 \pm 0.42 \mathrm{c}$ & $433.195 \pm 28.116 \mathrm{ab}$ & $5.38 \pm 0.370 \mathrm{a}$ & $0.931 \pm 0.027 \mathrm{a}$ \\
N270 & $9.18 \pm 0.51 \mathrm{c}$ & $453.621 \pm 18.402 \mathrm{ab}$ & $5.661 \pm 0.388 \mathrm{a}$ & $0.952 \pm 0.018 \mathrm{a}$ \\
$\mathrm{N} 312$ & $7.84 \pm 0.08 \mathrm{~d}$ & $461.726 \pm 22.605 \mathrm{ab}$ & $5.376 \pm 0.766 \mathrm{a}$ & $0.929 \pm 0.046 \mathrm{a}$ \\
\hline
\end{tabular}

\section{The fungal community structure}

We obtained 5 phylum groups and an unclassified group by comparing with the UNITE database (Fig. 1). The dominant phylum in the three types of soil was the same. Among the identified groups, Ascomycota was the most dominant phylum (53.33$64.60 \%)$, followed by Basidiomycota (17.51-34.42\%). The relative abundances of Ascomycota, Chytridiomycota and the unclassied in sandy soil were lower than those in the other two soils, but the abundances of Basidiomycota and Glomeromycota were the highest in sandy soil. The relative abundance of Zygomycota in black meadow soil was $2.95 \%$ higher than that in the sandy soil. With the $\mathrm{N}$ application level increased, the relative abundance of Ascomycota decreased, but Basidiomycota increased significantly. Moreover, Glomeromycota abundances were negatively correlated with the $\mathrm{N}$ application level (Table A3). 
We also identified fungi by genus to analyse the response of fungi to $\mathrm{N}$ application in three types of soil. The results showed that the top five most-changed genera level in three types of soil at the different $\mathrm{N}$ application levels. Cryptococcus, Fusarium, Holtermanniella, Thielaviopsis and Trichoderma were the most affected by the different types of soil (Fig. 2a). However, Alternaria, Geomyces, Gibberella, Rhizopus and Waitea changed significantly with the $\mathrm{N}$ application level (Fig. 2b). And Alternaria, Rhizopus and Waitea belonged to fungal pathogens, it suggested that excessed $\mathrm{N}$ application could increase fungal pathogens.

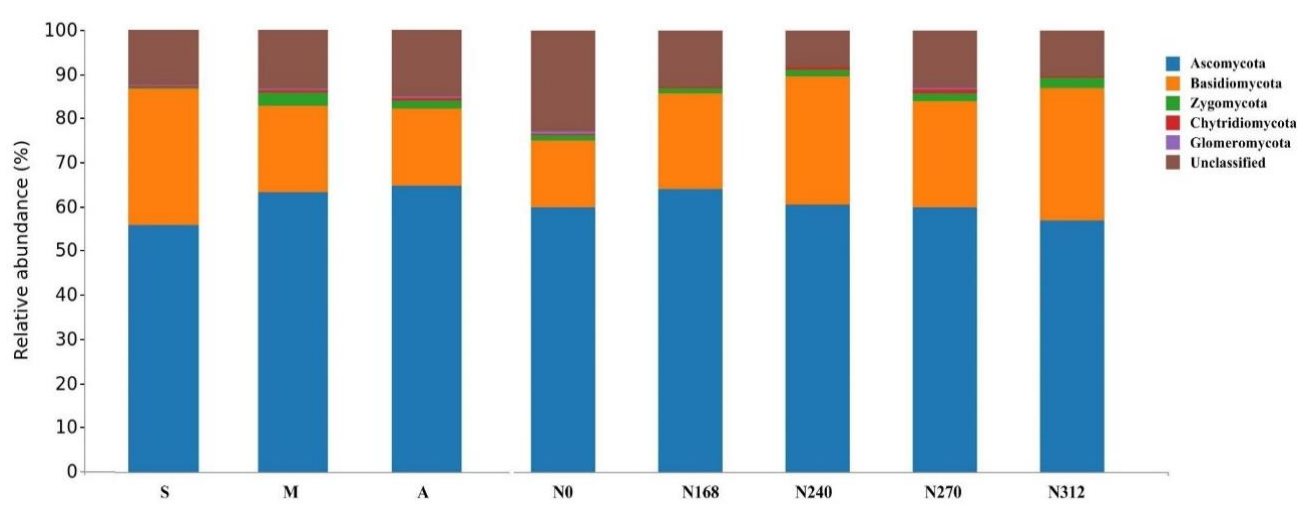

Figure 1. Relative abundance at the fungus phylum level of $N$ application levels in three types of soil

An UPGMA tree was used to calculate and analyse Beta diversity. The results showed that all samples were clustered into two main groups. Samples from the sandy soil and black meadow soil clustered into one clade, and samples from alluvial soil clustered in another clade. Samples in the sandy soil and black meadow soil also clustered into two clades; one clade was the N0 treatment, and the other treatments were in another clade (Fig. 3).

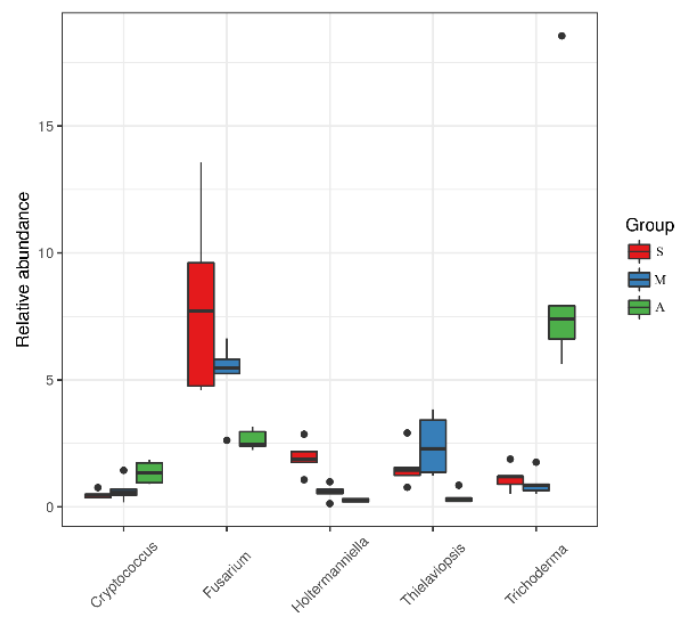

a

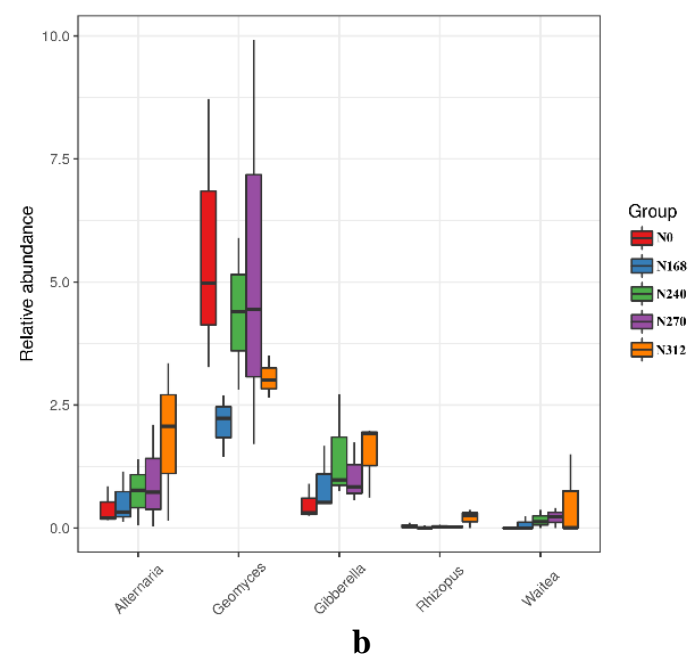

b

Figure 2. The top 5 changed relative abundance of fungi in genus level. (a) Fungi in different types of soil; (b) fungi in different $N$ applications 


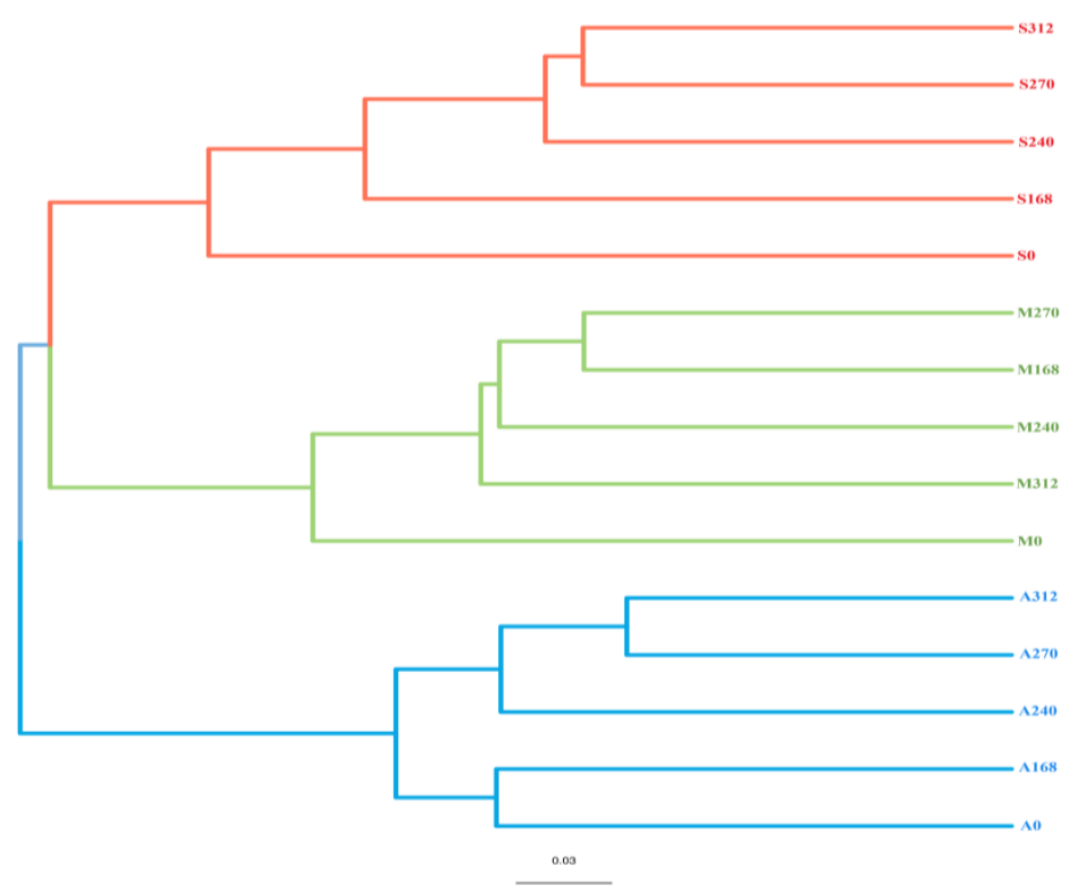

Figure 3. OPGAM_Tree analyze of soil fungal community under different $N$ application levels in three types of soil. Red indicates sandy soil, green indicates meadow black soil and bule indicates alluvial soil

To further investigate the effects of $\mathrm{N}$ application levels on fungal communities in different types of soil, the interdependence between the ITS transcript abundance of individual phylotypes and each of the environmental factors was investigated by redundancy analysis. Among the 10 environmental variables tested, all variables showed significant correlation with fungal community composition. We found that Humicola, Mortierella and Leptosphaeria were affected by most of the environmental factors, and they were all positively correlated with environmental factors. $\mathrm{pH}$ was significantly positively correlated with Fusicolla, Entrophosora, Verticillium, and Preussia but was negatively correlated with Trichocladium, Arthrinium, Penicillium and Cryptococcus. SOC was positively significantly correlated with Leptosphaeria, Thielaviopsis, Microdochium, Verticillium and Preussia and negatively correlated with Trichoderma, Cordyceps and Arthrinium. TK was significantly correlated with 7 fungal community compositions. TN was positively correlated with Humicola, Mortierella, Lestosphaeria, Lecanicillium and Chaetomium. And we found that $\mathrm{pH}, \mathrm{SOC}, \mathrm{TN}, \mathrm{MC}$ and TP were the main influences on the fungal community (Fig. 4).

\section{Discussion}

\section{Soil properties}

In agro-ecosystems, appropriate nitrogen input can provide the required nutrients for crop growth, but excessive application of nitrogen may have a negative impact on the soil environment. In this study, the physical and chemical properties in different types of soil were different, which was same as Jirků et al. (2013), as shown in Table 1. Wang et al. (2017) suggested that meadow black soil contained higher soil organic matter 
content and SOC, and was more fertile. In addition, the soil responses to nitrogen application were different. The content of AP decreased significantly with increasing levels of nitrogen application in the black meadow soil, but AP content increased in the sandy soil and the alluvial soil. In addition, the application of high nitrogen can lead to the accumulation of $\mathrm{NH}^{+}-\mathrm{N}$ and $\mathrm{NO}^{-}-\mathrm{N}$ in the soil. $\mathrm{N}$ application had no significant correlation with total nutrients $(P>0.05)$ (Yu et al., 2016), but it was significantly correlated with available nutrients $(P<0.05)$ (Table A1). Although the input of nitrogen did not increase the content of total nutrients in the soil, the accumulation of different forms of $\mathrm{N}$ promotes $\mathrm{N}$ cycling in the soil.

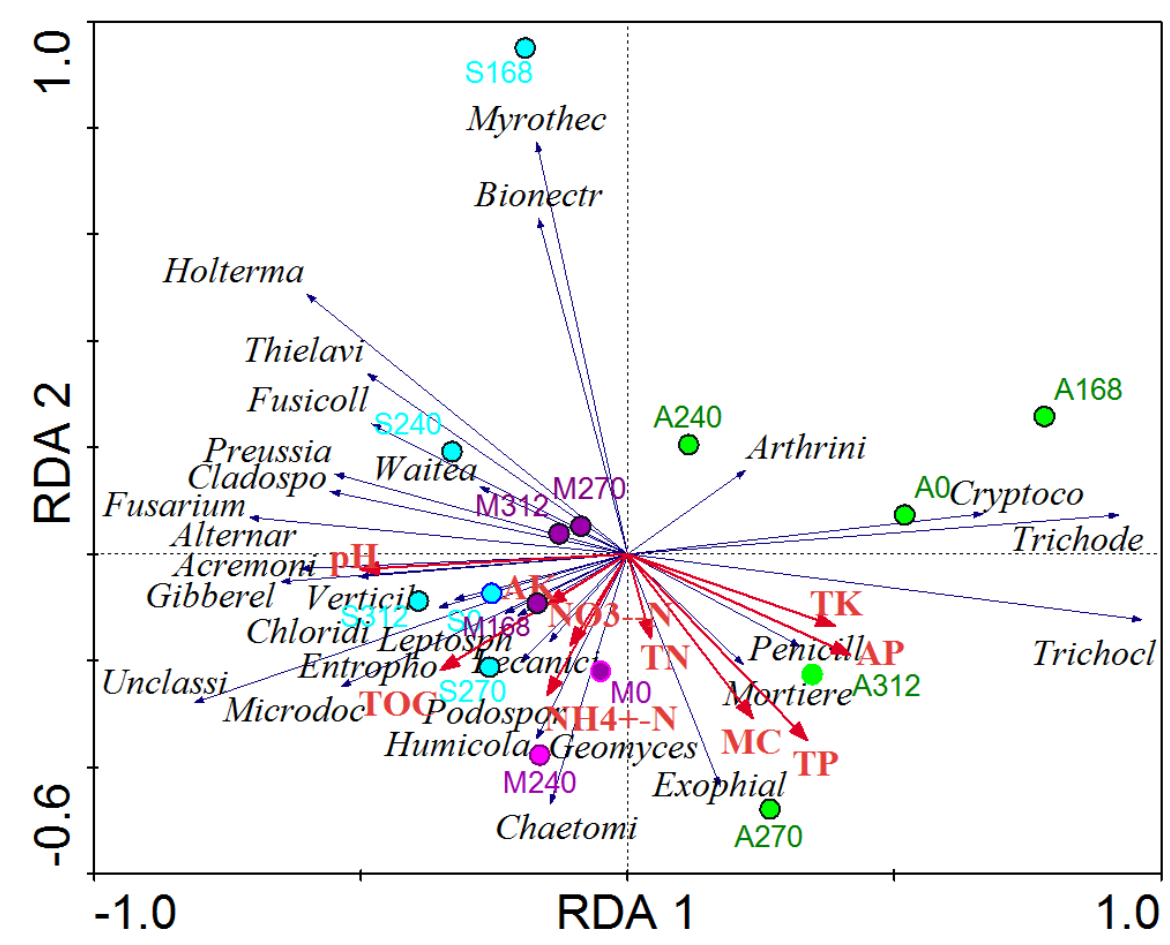

Figure 4. Triplots based on redundancy analysis (RDA) of $16 \mathrm{~S}$ rDNA finger print patterns, showing the contribution of environmental parameters to variability. Arrows indicate environmental factors and their relative effects on fungal community structure

The $\mathrm{pH}$ decreased significantly with increasing nitrogen application in the three types of soil. The continuous application of chemical fertilizers causes incomplete circulation of nitrogen in the soil, leading to soil acidification (Kamaa et al., 2011; Xia et al., 2015; Sun et al., 2015). The $\mathrm{pH}$ changes in the alluvial soil were relatively smaller than those in the sandy soil and the meadow black soil. The $\mathrm{pH}$ of the alluvial soil was the lowest when the nitrogen application level was $312 \mathrm{~kg} \cdot \mathrm{ha}^{-1}$, but it only decreased 0.37 compared to that in the control, whereas $\mathrm{pH}$ decreased by 0.7 and 0.92 in the sandy soil and black meadow soil, respectively. This may be because the buffer capacity of alluvial soil is relatively higher than that of sandy soil and meadow black soil (Chen et al., 2005).

\section{Rhizosphere soil fungal diversity}

Currently, the use of ITS sequencing technology to study the diversity and structure of fungal communities in the soil environment is becoming more common. Some 
researchers believe that fungal diversity is closely related to the soil ecological environment, which can lead to differences in the species and quantity of fungi in rhizosphere soil (Corey et al., 2008). Agricultural practices, such as tillage, fertilization, and machinery, which are used for crop management, have modified the physical and chemical properties of soils (Bissett et al., 2011, Suleiman et al., 2013) and consequently altered the soil fungal community diversity. In this paper, the diversity of fungi was relatively rich, and the diversity index was different in different soils (Jun et al., 2008). The fungal diversity in black meadow soil was higher than that in the other two soils, possibly because there was rich soil organic carbon in the black meadow soil, and soil organic carbon can provide nutrients for fungi (Jiang et al., 2018). The Chao 1 index under no nitrogen was the highest, and with the $\mathrm{N}$ application level increased, the Shannon and Simpson index had no significant changed, which was the opposite of the results of Qin et al. (2015) but the same as the results of Chanyarat et al. (2015). This may be because the fungal communities in different soils are different, and fungal community diversity changed significantly with the soil properties (Table A3). Liu et al. (2012a) found chemical fertilization could significantly alter the community diversity, and our results showed $\mathrm{N}$ application had negative relation with OTUs and fungal community diversity. This may be because excessive $\mathrm{N}$ application could increase the content of nitrate nitrogen, then decreased the $\mathrm{pH}$ and soil $\mathrm{pH}$ had significant negative relation with fungal diversity (Lamabam et al., 2012).

\section{Rhizosphere soil fungal structure}

The soil microbial community structure refers to the abundances and relative proportions of major microorganisms in soil (Bissett et al. 2011). In addition, the relative abundances of dominant fungal phyla in the rhizosphere soil change with nitrogen application (Yan et al., 2018). As shown in previous work, Ascomycota and Basidiomycota are dominant microorganisms that can frequently be found in maize soils (Yin et al., 2018). In this study, Ascomycota and Basidiomycota were the dominant fungal phyla among the three types of soils (Fig. 1), but the relative abundances of different samples from different soils were different. The relative abundance of Ascomycota in the sandy soil was lower than that in the other two soils. However, the relative abundance of Basidiomycota in the sandy soil was the highest of the three types of soil. This may be because of the different soil physical-chemical properties and nutrient contents in the three types of soil (Ruan et al., 2009). Specifically, Basidiomycota and Ascomycota could decompose animal and plant residues, cellulose and hemicellulose, etc. and provide nutrients for crops. We discovered Basidiomycota had a significant positive relationship with nitrogen application. Increasing levels of nitrogen addition favoured Basidiomycota, which may be ascribed to increases in low-lignin, high-cellulose substrate availability under elevated $\mathrm{N}$ conditions (Wang et al., 2015). However, in black meadow soil, the relative abundance of Ascomycota increased under N168 but decreased with excess N. This indicated that the dominant fungal community response to $\mathrm{N}$ application in different soils is different. The unclassified fungal phyla decreased with nitrogen addition, indicating that nitrogen application has a positive effect on known fungal communities. In addition, we found that the relative abundance of Chytridiomycota and Glomeromycota which showed linear increases with $\mathrm{CO}_{2}$ (Procter et al., 2014) altered significantly with $\mathrm{N}$ application. Glomeromycota abundance decreased with increasing $\mathrm{N}$ application levels (Liu et al., 2012b). But Chytridiomycota relative abundance was 
higher than Glomeromycota, and the relative abundance of Chytridiomycota increased with $\mathrm{N}$ application. We also found that abundances of Cryptococcus and Holtermanniella, belonging to the Basidiomycota phyla, and Fusarium, Thielaviopsis and Trichoderma, belonging to the Ascomycota phyla, were significantly different among three types of soil. Moreover, Alternaria, (P_Ascomycota), Rhizopus (P_Zygomycota) and Waitea (P_Basidiomycota) showed significant positive responses to nitrogen. This suggested $\mathrm{N}$ application could increase the transmission of fungal pathogens. In these most-changed fungi, Fusarium is an example of a fungal genus in the class Sordariomycetes and is known to function in denitrification. Sordariomycetes was the only fungal class that responded to $\mathrm{N}$ addition (Mueller et al., 2015). In this study, Fusarium had a positive response to $\mathrm{N}$ application levels, and it was highest in the sandy soil (Fig. 3), which is the opposite of the results found by Lauber et al. (2008) and Mueller et al. (2015). This may be because Fusarium has different responses to N addition in different soils.

Soil fungal community structure is an important index for measuring soil quality and maintaining soil fertility (Swer et al., 2011). Moreover, the fungal community notably changes in different types of soil (Zhang et al., 2013). In this study, the Beta diversity of soil fungal colonies across different soils under different levels of nitrogen using an UPGMA tree showed that all samples clustered into two large groups, i.e., the sites of the sandy soil and black meadow soil were clustered into one clade, while those of alluvial soil were clustered into the other clade. In these two large groups, the samples clustered into two clades: one clade included the N0 samples, and the other included the samples with $\mathrm{N}$ application. However, the samples of N0 and N168 were closer to each other than to the others in the alluvial soil. This structure indicates that the $\mathrm{N}$ fertilizer effects on fungal community structure in different types of soils were different: the fungal community rapidly increased with the level of $\mathrm{N}$ fertilizer in sandy soil, but the fungal community did not increase significantly with $\mathrm{N}$ fertilizer until the level was $168 \mathrm{~kg} \cdot \mathrm{ha}^{-1}$ (Girvan et al., 2004). As the $\mathrm{N}$ application levels increased, the soil physical and chemical properties changed, and the soil fungi had a significant relationship with the soil environment (Fig. 4). Huang et al. (2017) showed that low levels of bio-organic fertilizer had little effect on soil microorganisms, but high levels of bio-organic fertilizer could change the soil microbial community.

To determine the effects of soil physical-chemical properties on the fungal community, we used a heatmap analysis of the relative abundance of 30 main fungal taxa (Fig. 4). The soil physical-chemical properties had a significant effect on the fungal community (Ana et al., 2010). However, Carles et al. (2016) considered that drying procedures had no effect on fungal community composition or on fungal diversity. In this paper, soil MC had a positive effect on Holtermanniella and a negative effect on Chaetomium, Leptosphaeria, Mortierella and Humicola, possibly because the fungal community was collected from different soils or in different seasons and the response of the fungal community to different soils varies (Chemidlin et al., 2014). In this paper, $\mathrm{pH}, \mathrm{SOC}, \mathrm{MC}$ (Ke et al., 2016), TN and TP had a significant influence on the fungal community. Although the soil physical-chemical properties did not strongly change with the $\mathrm{N}$ application level, they were significantly different in different types of soil. Therefore, we concluded that the most important factor for the fungal community was the soil type, followed by the $\mathrm{N}$ application level. As the level of nitrogen application increased, the soil active nutrients were altered, and the applied $\mathrm{N}$ could improve nutrient availability for soil fungi. 


\section{Conclusions}

Our study revealed that the responses of fungal community to long-term $\mathrm{N}$ application. The diversity of soil fungal communities was higher in black meadow soil than in sandy soil and alluvial soil due to the higher soil nutrition in black meadow soil. Our results also confirmed that $\mathrm{N}$ application level had no significant effect on fungal diversity, but had significantly correlated with soil physical-chemical properties. Then $\mathrm{pH}, \mathrm{MC}, \mathrm{TN}$ and TP could alter soil fungal community diversity and structure. From the point of view of soil fungal structure, it seemed that increasing $\mathrm{N}$ application level could increase $\mathrm{CO}_{2}$ emissions and transmission of fungal pathogens. Ascomycota abundance was highest in S270, M168 and A240 respectively. Here, we suggest that the amount of fertilizer application should be based on different types of soil, and the ordination of $\mathrm{N}$ application should be sandy soil > alluvial soil > meadow black soil. In this way, it could not only reduce the application amount of nitrogen fertilizer, while reducing environmental pollution, but also could optimize the structure of fungal community.

Acknowledgements. This work is a contribution to Jilin Province Science and Technology Development Plan Project (20200403069SF), National Key Research and Development Project (2017YFD0300405-4), Jilin Province Science and Technology Development Plan Project (20160307006NY).

\section{REFERENCES}

[1] Ana, R., Joséj, P. (2010): Effect of fire severity and site slope on diversity and structure of the ectomycorrhizal fungal community associated with post-fire regenerated Pinus pinaster Ait. seedlings. - Forest Ecology Management 260(3): 361-369.

[2] Bi, L. M., Yu, W. T., Jiang, Z. S., Zhou, H., Shen, S. M. (2010): Effects of fertilization and soil management on microbial biomass and community. - Acta Ecologica Sinica 30(1): 32-42.

[3] Bissett, A., Richardson, A. E., Baker, G., Thrall, P. H. (2011): Long-term land use effects on soil microbial community structure and function. - Applied Soil Ecology 51(1): 66-78.

[4] Carles, C., Javier, P., Joan, P. J., Martinez, D. A., Josu, G. A., Jose, A. B. (2016): Soil drying procedure affects the DNA quantification of Lactarius vinosusbut does not change the fungal community composition. - Mycorrhiza 26(8): 799-808.

[5] Chanyarat, P. L., Yun, K. Y., Naga, R. P. K., Lonhienne, T. G., Robinson, N., Hugenholtz, P., Ragan, M. A. (2015): Nitrogen fertilizer dose alters fungal communities in sugarcane soil and rhizosphere. - Scientific Reports 5: 8678.

[6] Chemidlin, P. B., Nicolas, D. S., Thioulouse, J., Lelièvre, M., Saby, N. P. A., Jolivet, C., Dominique, A., Pierre, P., Philippe, L., Lionel, R. (2014): Similar processes but different environmental filters for soil bacterial and fungal community composition turnover on a broad spatial scale. - PLoS ONE 9(11): e111667.

[7] Chen, C. L., Jiang, A. F., Ren, X. J., Ding, X., Chang, X. (2005): Studies on acidic buffering capability in different soil texture types in moisture soil area. - Henan Agriculture Science 34(10): 64-66.

[8] Corey, D. B., Amanda, K. B., Joy, B., Jorge, M. V. (2008): Root exudates regulate soil fungal community composition and diversity. - Applied and Environmental Microbiology 74(3): 738-744.

[9] Cui, J. T., Li, Y. N., Wang, C. Y., Kyung, S. K., Wang, T. Y., Liu, S. X. (2018): Characteristics of rhizosphere bacterial community across different cultivation years in Saline-alkaline paddy soil of Songnen plain of China. - Canadian Journal of Microbiology 64(12): 925-936. 
[10] Deng, J. C., Liao, B., Ye, M., Deng, D. M., Lan, C. Y., Shu, W. S. (2007): The effects of heavy metal pollution on genetic diversity in zinc/cadmium hyperaccumulator Sedum alfredii populations. - Plant Soil 297(1-2): 83-92.

[11] Girvan, M. S., Bullimore, J., Ball, A. S., Pretty, J. N., Osborn, A. M. (2004): Responses of active bacterial and fungal communities in soils under winter wheat to different fertilizer and pesticide regimens. - Applied and Environmental Microbiology 70(5): 2692-2701.

[12] Huang, N., Wang, W., Yao, Y., Zhu, F., Wang, W., Chang, X. (2017): The influence of different concentrations of bio-organic fertilizer on cucumber Fusarium wilt and soil microflora alterations. - PLoS ONE 12(2): e0171490.

[13] Huang, Y. J., Pan, H., Wang, Q. L., Ge, Y. Y., Liu, W. X., Peter, C. (2019): Enrichment of the soil microbial community in the bioremediation of a petroleum-contaminated soil amended with rice straw or sawdust. - Chemosphere 224: 265-271.

[14] Jiang, Y., Qian, H., Wang, X., Chen, L. J. (2018): Nematodes and microbial community affect the sizes and turnover rates of organic carbon pools in soil aggregates. - Soil Biology Biochemistry 119: 22-31.

[15] Jirků, V., RadkaKodešová, R., Antonín, N., Mühlhanselová, M., Zigová, A. (2013): Temporal variability of selected chemical and physical properties of topsoil of three soil types. - Egu General Assembly 15: 43-58.

[16] Joergensen, R. G., Wichern, F. (2008): Quantitative assessment of the fungal contribution to microbial tissue in soil. - Soil Biology and Biochemistry 40: 29772991.

[17] Jun, T. Z., Chen, Y., Chang, C. H., An, L. Z. (2008): The diversity of soil fungi and its relations with fertility factors in Taxus chinensis (Pilg.) Rehd community of Xiaolongshan of Tianshui City. - Research of Environmental Sciences 21(1): 128-132.

[18] Kamaa, M., Mburu, H., Blanchart, E., Licingstone, C., Jean, L. C., Catherine, K., Didier, L. (2011): Effects of organic and inorganic fertilization on soil bacterial and fungal microbial diversity in the Kabete long-term trial, Kenya. - Biology and Fertility of Soils 47(3): 315-321.

[19] Ke, D., Binu, T., Itumeleng, M., Woosung, K., Li, N., Chu, H. Y., Jonathan, A. (2016): Soil fungal community development in a high Arctic glacier foreland follows a directional replacement model, with a mid-successional diversity maximum. - Science Report 6(1): 26360.

[20] Kowalchuk, G. A., Gerards, S., Woldendorp, J. W. (1997): Detection and characterization of fungal infections of Ammophila arenaria (marram grass) roots by denaturing gradient gel electrophoresis of specifically amplified 18S rDNA. - Applied and Environmental Microbiology 63(10): 3858-3865.

[21] Lamabam, S. D., Polashree, K., Fenella, M. W. N., Joshi, S. R. (2012): Diversity of culturable soil micro-fungi along altitudinal gradients of eastern Himalayas. Mycobiology 40(3): 151-158.

[22] Lauber, C. L., Strickland, M. S., Bradford, M. A., Fierer, N. (2008): The influence of soil properties on the structure of bacteria land fungal communities across land-use types. - Soil Biol Biochem 40(9): 2407-2415.

[23] Laura, B. M. G., Miranda, J. D. D., Pugnaire, F. I. (2012): Impacts of changing rainfall patterns on mycorrhizal status of a shrub from arid environments. - European Journal of Soil Biology 50: 64-67.

[24] Li, M. S (2018): Changes of Microbial Population Structure in Corn Rhizosphere under Different Nitrogen Application Levels. - Jilin Agricultural University, Changchun.

[25] Lijbert, B., Peter, C. D. R., George, G. B. (2007): Soil biodiversity for agricultural sustainability. - Agriculture Ecosystems and Environment 121(3): 233-244.

[26] Lin, S. H., Li, W., Zhuang, W. J., Quan, Y. S., Dong, D. W., Wang, D. Y. (2018): Study on Maize Planting in Jilin Province. - Jinlin Agriculture 23: 54. 
[27] Liu, P. F., Wang, H. Y. (2012a): Effects of organic and chemical fertilizer applications on the diversity of soybean rhizobia. - Chinese Journal of Ecology 31(6): 1468-1472.

[28] Liu, Y., Shi, G., Mao, L., Cheng, G., Jiang, S., Ma, X., An, L., Du, G., Collins Johnson, N., Feng, H. (2012b): Direct and indirect influences of 8yr of nitrogen and phosphorus fertilization on Glomeromycota in an alpine meadow ecosystem. - New Phytologist 194(2): 523-535.

[29] Mueller, R. C., Belnap, J., Kuske, C. R. (2015): Soil bacterial and fungal community responses to nitrogen addition across soil depth and microhabitat in an arid shrubland. Frontiers in Microbiology 6: 891.

[30] Procter, A. C., Ellis, J. C., Fay, P. A., Polley, H. W., Jackson, R. B. (2014): Fungal community responses to past and future atmospheric co2 differ by soil type. - Applied Environmental Microbiology 80(23): 7364-7377.

[31] Qin, X. M., Yi, Z., Li, T., Long, G. Q. (2015): Effects of maize and potato intercropping on rhizosphere microbial community structure and diversity. - Acta Agronomica Sinica 6: 919.

[32] Qu, Z. M., Qi, X. C., Wang, J., Chen, Q., Li, C. L. (2019): Effects of nitrogen application rate and topdressing times on yield and quality of Chinese cabbage and soil nitrogen dynamics. - Environmental Pollutants and Bioavailability 31(1): 1-8.

[33] Ruan, X. D., Zhang, H. W., Sun, D. X., Cai, Y. H., Li, X. Y. (2009): Fungal community structures in root zone of dominant vegetations of different layers in Pinus tabulaeformis broad-leaved mixed forest in Qianshan by PCR-DGGE. - Journal of Northeast Forestry University 37(5): 48-50.

[34] Sall, S. D., Dominique, M., Yacine, N., Jean-Luc, C. (2006): Does cropping modify the decomposition function and the diversity of the soil microbial community of tropical fallow soil. - Applied Soil Ecology 31(3): 211-219.

[35] Suleiman, A. K. A., Manoeli, L., Boldo, J. T., Pereira, M. G., Roesch, L. F. W. (2013): Shifts in soil bacterial community after eight years of land-use change. - Systematic Applied Microbiology 36(2): 137-144.

[36] Sun, R., Zhang, X. X., Guo, X., Wang, D., Chu, H. (2015): Bacterial diversity in soils subjected to long-term chemical fertilization can be more stably maintained with the addition of livestock manure than wheat straw. - Soil Biology and Biochemistry 88(4): 918.

[37] Swer, H., Dkhar, M., Kayang, H. (2011): Fungal population and diversity in organically amended agricultural soils of Meghalaya India. - Journal of Organic Systems 6: 3-12.

[38] Tian, R., Huang, C., Deng, L., Fang, C., Lei, Y. (2018): Environmental risk assessment and trend simulation of non-point source pollution of chemical fertilization in Sichuan province, China. - Chinese Journal of Eco-Agriculture 26(11): 1739-1751.

[39] Wang, J., Bao, J., Su, J., Li, X., Chen, G., Ma, X. (2015): Impact of inorganic nitrogen additions on microbes in biological soil crusts. - Soil Biology and Biochemistry 88: 303 313.

[40] Wang, Q., Liu, F., Gao, Z., Jia, H. (2017): Effect of improving black soil and crop yield by using soil layer up-down fallow technology. - Transactions of the Chinese Society of Agricultural Engineering 33(6): 100-106.

[41] Wilson, H. (2013): Climate change effects on arbuscular mycorrhizal fungi and prairie plants along a mediterranean climate gradient. - Dissertations Theses Gradworks 51(5): 75 .

[42] Wood, J. R., Dickie, I. A., Moeller, H. V., Peltzer, D. A., Bonner, K. I., Rattray, G., Wilmshurst, J. M. (2015): Novel interactions between non-native mammals and fungi facilitate establishment of invasive pines. - Journal of Ecology 103(1): 121-129.

[43] Xia, X., Shi, K., Huang, Q. R., Li, D. M., Liu, M. Q., Li, H. X., Hu, F., Jiao, J. G. (2015): The changes of microbial community structure in red paddy soil under long-term fertilization. - Acta Pedologica Sinica 52(3): 697-705. 
[44] Xu, X., Stange, C. F., Richter, A., Wanek, W., Kuzyakov, Y. (2008): Light affects competition for inorganic and organic nitrogen between maize and rhizosphere microorganisms. - Plant and Soil 304(1): 59-72.

[45] Yamamoto, A., Akiyama, H., Nakajima, Y., Hoshino, Y. T. (2017): Estimate of bacterial and fungal $\mathrm{N}_{2} \mathrm{O}$ production processes after crop residue input and fertilizer application to an agricultural field by $15 \mathrm{~N}$ isotopomer analysis. - Soil Biology and Biochemistry 108: 9-16.

[46] Yan, H. T., Yin, Q. Y., Ding, S. S., Ren, T. B., Xu, J. L., Zhong, H., Gao, Q., Liu, G. S. (2018): Effect of biochar amendment on physicochemical properties and fungal community structures of cinnamon soil. - Environment Science 2412-2419.

[47] Yin, A., Jia, Y., Qiu, T., Qiu, T., Gao, M., Cheng, S. T., Wang, X. M., Sun, Y. M. (2018): Poly- $\gamma$-glutamic acid improves the drought resistance of maize seedlings by adjusting the soil moisture and microbial community structure. - Applied Soil Ecology S0929139318302324.

[48] Yu, H., Gao, Q., Shao, Z., Ying, A., Sun, Y., Liu, J., Mao, W., Zhang, B. (2016): Decreasing nitrogen fertilizer input had little effect on microbial communities in three types of soils. - Plos One 11(3): e0151622.

[49] Zhang, H. H., Tang, M., Chen, H., Zheng, C. L. (2010): Effects of inoculation with ectomycorrhizal fungi on microbial biomass and bacterial functional diversity in the rhizosphere of Pinus tabulaeformis seedlings. - European Journal of Soil Biology 46(1): 55-61.

[50] Zhang, X. F., Zhao, L., Xu, S. J., Liu, Y. Z., Liu, H. Y., Cheng, G. D. (2013): The influence of soil moisture effect on bacterial and fungal community in Beilu River (Tibetan Plateau) permafrost soils with different vegetation types. - Journal of Applied Microbiology 114(4): 1054-1065.

[51] Zhang, H. F., Liu, H. M., Zhao, J. N., Li, G., Lai, X., Li, J., Wang, H., Yang, D. L. (2018): Respond of soil fungal community structure to nitrogen and water addition in Stipa baicalensis steppe. - Acta Ecologica Sinica (38)1: 195-205.

[52] Zhao, S., Liu, D., Ling, N., Chen, F., Fang, W., Shen, Q. (2014): Bio-organic fertilizer application significantly reduces the Fusarium oxysporum population and alters the composition of fungi communities of watermelon fusarium wilt. rhizosphere soil. Biology Fertility of Soils 50(5): 765-774.

[53] Zheng, S. X., Hu, J. L., Jiang, X. F., Ji, F. Q., Zhang, J. B., Yu, Z. N., Lin, X. G. (2013): Long-term fertilization regimes influence FAME profiles of microbial communities in an arable sandy loam soil in Northern China. - Pedobiologia 56(4): 179-183.

[54] Zhou, J., Jiang, X., Zhou, B. K., Zhao, B. S., Ma, M. C., Guan, D. W., Li, J., Chen, S. F., Cao, F. M., Shen, D. L., Qin, J. (2016): Thirty-four years of nitrogen fertilization decreases fungal diversity and alters fungal community composition in black soil in northeast China. - Soil Biology and Biochemistry 95: 135-143.

\section{APPENDIX}

Table A1. Correlation analysis between soil physical-chemical properties and N application levels

\begin{tabular}{c|c|c|c|c|c|c|c|c|c|c}
\hline & $\mathbf{p H}$ & $\mathbf{M C}$ & $\mathbf{S O C}$ & $\mathbf{T N}$ & $\mathbf{N H}_{4}{ }^{+}-\mathbf{N}$ & $\mathbf{N O}_{3}-\mathbf{N}$ & $\mathbf{T P}$ & $\mathbf{A P}$ & $\mathbf{T K}$ & AK \\
\hline $\mathrm{R}$ & $\mathbf{- 0 . 9 8}^{* *}$ & $\mathbf{- 0 . 9 8}^{* *}$ & 0.386 & 0.287 & $\mathbf{0 . 8 9 3}^{*}$ & $\mathbf{0 . 8 9}^{*}$ & -0.11 & 0.07 & -0.8 & -0.17 \\
P-value & $\mathbf{0 . 0 0}$ & $\mathbf{0 . 0 0}$ & 0.52 & 0.64 & $\mathbf{0 . 0 4}$ & $\mathbf{0 . 0 4}$ & 0.86 & 0.91 & 0.10 & 0.78 \\
\hline
\end{tabular}

MC is the moisture content of soil; SOC is Soil organic carbon content; TN is soil total nitrogen; TP is soil total nitrogen; TK is soil total potassium; $\mathrm{NH}_{4}^{+}-\mathrm{N}$ is ammonium nitrogen; $\mathrm{NO}_{3}^{-}-\mathrm{N}$ is nitrate nitrogen; $\mathrm{AP}$ is available phosphorus; $\mathrm{AK}$ is available potassium. **indicates $p<0.01, *$ indicates $p<0.05$ 
Table A2. Correlation analysis between fungal community and soil physcial-chemical properties

\begin{tabular}{c|c|c|c|c|c|c|c|c}
\hline \multirow{2}{*}{} & \multicolumn{2}{|c|}{ chao1 } & \multicolumn{2}{c|}{ Shannon } & \multicolumn{2}{c|}{ Simpson } & \multicolumn{2}{c}{ OTU } \\
\cline { 2 - 9 } & R & P-value & R & P-value & R & P-value & R & P-value \\
\hline $\mathrm{pH}$ & 0.331 & 0.228 & -0.024 & 0.932 & -0.104 & 0.711 & $-0.620^{*}$ & 0.014 \\
$\mathrm{MC}$ & 0.469 & 0.078 & $0.523^{*}$ & 0.046 & 0.227 & 0.415 & $-.0602^{*}$ & 0.018 \\
$\mathrm{SOC}$ & $0.707^{* *}$ & 0.030 & $0.587^{*}$ & 0.022 & 0.025 & 0.928 & $-0.672^{* *}$ & 0.006 \\
$\mathrm{TN}$ & $0.562^{*}$ & 0.290 & $0.559^{*}$ & 0.030 & -0.310 & 0.261 & -0.337 & 0.219 \\
$\mathrm{NH}^{+}-\mathrm{N}$ & 0.498 & 0.059 & 0.307 & 0.265 & -0.409 & 0.130 & $-0.644^{* *}$ & 0.010 \\
$\mathrm{NO}^{-}-\mathrm{N}$ & 0.485 & 0.067 & $0.617^{*}$ & 0.014 & -0.057 & 0.841 & $-0.720^{* *}$ & 0.002 \\
$\mathrm{TP}$ & 0.473 & 0.075 & $0.638^{*}$ & 0.010 & -0.101 & 0.720 & $-0.608^{*}$ & 0.016 \\
$\mathrm{AP}$ & 0.277 & 0.318 & 0.478 & 0.072 & 0.056 & 0.842 & -0.398 & 0.142 \\
$\mathrm{TK}$ & 0.392 & 0.149 & 0.307 & 0.266 & $0.556^{*}$ & 0.031 & $-0.530^{*}$ & 0.042 \\
$\mathrm{AK}$ & 0.656 & 0.008 & 0.470 & 0.077 & -0.019 & 0.946 & $-0.936^{* *}$ & 0.000 \\
$\mathrm{~N}$ & -0.020 & 0.944 & -0.116 & 0.681 & 0.060 & 0.830 & -0.016 & 0.955 \\
\hline
\end{tabular}

Table A3. Correlation analysis between fungal phylum and $N$ application levels

\begin{tabular}{c|c|c|c|c|c|c}
\hline & Ascomycota & Basidiomycota & Unclassified & Zygomycota & Chytridiomycota & Glomeromycota \\
\hline $\mathrm{R}$ & -0.55 & $\mathbf{0 . 8 9}$ & $\mathbf{- 0 . 9 7}$ & -0.81 & -0.66 & $\mathbf{- 0 . 9 3}$ \\
$P$-value & 0.34 & 0.05 & 0.01 & 0.10 & 0.22 & 0.02 \\
\hline
\end{tabular}

Table A4. The location of the sampling sites

\begin{tabular}{c|c|c|c}
\hline Soil types & Sampling location & \multicolumn{2}{|c}{ Latitude and longitude } \\
\hline Sandy soil & Fujiajie country & $43^{\circ} 21^{\prime} \mathrm{N}$ & $124^{\circ} 05^{\prime} \mathrm{E}$ \\
Meadow black soil & Sankeshu country & $43^{\circ} 20^{\prime} \mathrm{N}$ & $124^{\circ} 00^{\prime} \mathrm{E}$ \\
Alluvial soil & Wangjiaqiao country & $43^{\circ} 15^{\prime} \mathrm{N}$ & $124^{\circ} 29^{\prime} \mathrm{E}$ \\
\hline
\end{tabular}

